\title{
Editorial
}

\section{Mathematical Models for Supply Chain Management}

\author{
Young Hae Lee, ${ }^{1}$ Paulina Golinska-Dawson, ${ }^{2}$ and Jei-Zheng $\mathrm{Wu}^{3}$ \\ ${ }^{1}$ Department of Industrial and Management Engineering, Hanyang University, Ansan 15588, Republic of Korea \\ ${ }^{2}$ Faculty of Engineering Management, Poznan University of Technology, 60965 Poznan, Poland \\ ${ }^{3}$ Department of Business Administration, Soochow University, Taipei 10048, Taiwan \\ Correspondence should be addressed to Young Hae Lee; yhlee@hanyang.ac.kr
}

Received 20 March 2016; Accepted 31 March 2016

Copyright (C) 2016 Young Hae Lee et al. This is an open access article distributed under the Creative Commons Attribution License, which permits unrestricted use, distribution, and reproduction in any medium, provided the original work is properly cited.

\section{Introduction}

Business leaders today are facing many challenges including cost, tax laws, skills, material availability, and new market entry and others have driven organizations to redesign and reconfigure their supply chains continually. As supply chains become globalized the complexities to manage and control those globalized supply chains will also increase and that usually results in inadequate existing experience and intuition. Therefore, to overcome that inadequacy the use of mathematical models becomes necessary.

The attention towards the use of mathematical models to optimize supply chain has been increasing, mainly because of their lower cost and greater capability. In supply chain management the use of mathematical modeling is not specific to any particular level; those can be used at any level (strategic, tactical, or operational), considering the factors like transportation routing, distribution networks, or warehouse operations. Mathematical modeling approaches that are usually considered in supply chain problems include linear programming, mixed-integer/integer linear programming, nonlinear programming, multiobjective programming, fuzzy mathematical programming, stochastic programming, heuristics algorithms, and metaheuristics and hybrid models.

The articles in this special issue speak of development of advance mathematical modeling approached to tackle complex global supply chain management challenges. The following sections briefly explain the outcome of published articles in this special issue. The next section is divided into several key research areas based on publications.

\section{Supply Chain Quality Management}

H. J. Kim et al. proposed strategies for improving supply chain quality in buyer-supplier relations. This study analyzes the efficiency of supply chain quality management (SCQM) by grouping buyers and suppliers and conducting an empirical analysis of aspects affecting SCQM efficiency from the supplier's perspective. Another paper under this research umbrella is published by M. S. Memon et al. for increasing product safety and quality. They analyzed impact of traceability optimization on supply chain operational efficiency and shareholder profit under adverse recall crisis. Their analysis showed that reduction in traceability level increases the expected shareholders losses while decreasing the operational costs. The proposed model will help managers to optimally set the production batch sizes in order to reduce the product recall impact.

\section{Supply Chain Contracts}

B. Sarkar et al. illustrated a channel coordination and quantity discount between a vendor and a buyer with single-setup multidelivery (SSMD) strategy to reduce the joint total cost among supply chain players. The benefit of the coordination between a buyer and a vendor is considered as the vendor requests to the buyer for changing the ordering quantity such that the vendor can be benefited from lower inventory costs. After accepting the buyer's condition, the vendor compensates the buyer for his increased inventory cost and gives consent for additional savings by offering a quantity 
discount. Also, B. Sarkar et al. considered the effect of carbon emission cost reduction during transportation in industry sector. During transporting items, fixed and variable carbon emission costs for both vendor and buyer are used in this paper. It is assumed that the vendor's setup cost is variable and delivery lot sizes are unequal and variable. After receiving the lot, the buyer conducts an inspection procedure and defective items are returned to vendor for reworking operation. The main purpose for developing this model is to reduce the carbon emission cost for vendor-buyer system. H. Zhang et al. designed supply chain contracts, under which the supply chain with double sided disruption can be coordinated. Firstly, the centralized decision-making models are applied to find the optimal price and quantity under three cases as the baseline. The different cases are divided by the different relationship between the product cost disruption and the demand disruption. Secondly, two different types of contracts are introduced to coordinate the whole supply chain. And it is found out that the gap between the demand disruption and the product cost disruption is the key factor to influence the supply chain coordination. Q. Pang et al. studied how to deal with emergencies by revenue-sharing contract with effort dependent demand. They focused on the three aspects. First of all, this study analyzed the impact of effort on the supply chain coordination. Furthermore, they studied the impact of emergencies on the supply chain coordination and put forward two forms of the revenuesharing contracts which have an antidisruption ability so as to improve the capacity of handling emergencies. Finally, based on the hypothesis that the demand and the retail price satisfy an additive form, this research optimizes the revenue-sharing contract model and gives out the method to calculate the optimal inventory quantity and effort level. R. Wang et al. investigated supply chain coordination issues and explored the impact of promotional competition on the retailers' optimal order quantity, the supplier's optimal production decision, and supply chain coordination. T. Shu et al. explored a coordination model for a three-echelon supply chain via the combined option and back contracts. Firstly, this paper integrated the advantages of the option contract and the buyback contract. Secondly, to be closer to the real-life environment, study considered the three-echelon supply chain model with two different suppliers (called dual sourcing purchase), one distributor and one retailer. In addition, considering the recent situation, we cannot neglect the disruption risk factors in the supply chain. Consequently, supply disruption risk factors are considered in this paper. W. Liu et al. took the MCLS environment into consideration and introduce the customized level as an important factor for the design of a revenue-sharing contract mechanism. Second, this article is based on the logistics service supply chain of two echelons and establishes a revenue-sharing mechanism model in two relations by expanding the "one to one" relationship between the LSI and FLSP to "one to $N$." Finally, this paper aims at the maximum of fair entropy and setting improved fair entropy as the objective function of the model and then explores the influence of customized level on supply chain fair entropy, and some interesting findings are obtained. Y.-K. Lin et al. investigated a support service supply chain for coordinating with a local thirdparty logistics provider by arms offset program's intervention and develop a performance-based contracting framework for the coordinating problem, which remains scarce in the literatures. They proposed performance-based contracting framework to evaluate payments and profits for the support service using a game-theoretical approach with principalagent model.

\section{Inventory Management}

C. Gao et al. considered optimal pricing and manufacturing control of a continuous-review inventory system with remanufacturing. The objective of this study is to maximize the expected total discounted profit over an infinite planning horizon. They characterize the structural properties of the optimal policy through the optimality equation. Specifically, the optimal manufacturing policy is a base-stock policy with the base-stock level nonincreasing in the return inventory level. The optimal pricing policy is also a threshold policy, where the threshold level is nonincreasing in the return inventory level. R.-Q. Zhang et al. formulated the inventory model with partial backordering considering the purchase delay of the backordered customers and assuming that the backorder demand rate is proportional to the remaining backordered demand. Particularly, we model the problem by introducing a new inventory cost component of holding the backordered items, which has not been considered in the existing models. They proposed an algorithm with a two-layer structure based on Lipschitz Optimization (LO) to minimize the total inventory cost. Y. Cheng et al. investigated optimal choices for the e-tailer with inventory rationing, hybrid channel strategies, and service level constraint under multiperiod environment. Based on different operational conditions, five mathematical models are proposed for the e-tailer who faces two types of fuzzy demand and a framework is designed to illustrate the e-tailer's operation in different models. This paper presented the advantages of inventory rationing and hybrid channel strategies and analyzes the influences of channel differences variability on optimal choices for the e-tailer, where the channel differences include margin difference of priority and margin difference of channel. Through computer simulation, the optimal choices for the e-tailer under different multiperiod environments are obtained, and the influences of margin difference of priority and margin difference of channel on the e-tailer's optimal choices are also examined. J. Jiang and S.-C. Rim extended their previous study to the general BOM (G-BOM) in which parts in the BOM can have more than one immediate parent and present a new solution procedure using genetic algorithm. In their previous study they presented a model to determine the optimal position and quantity of WIPI for a given simple bill of material (S-BOM), in which any part in the BOM has only one immediate parent node.

\section{Supplier Selection and Strategic Alliance}

A. Kawa and W. W. Koczkodaj proposed a framework to assess suppliers by using consistency-driven pairwise 
comparisons for tangible and intangible criteria. The proposed model combines assessments of both types of criteria. The main contribution of this paper is the presentation of an extension framework for the selection of suppliers in a procurement process. The final weights are computed from relative pairwise comparisons. For the needs of the paper, surveys were conducted among Polish managers dealing with cooperation with suppliers in their enterprises. This study presents a theoretical framework for building a logical model for evaluation of suppliers. It also proposes how the final weights may be obtained from relative pairwise comparisons. B. Kang et al. developed a methodology for supplier selection using Z-numbers considering information transformation. It includes two parts: one solves the issue of how to convert Z-number to the classic fuzzy number according to the fuzzy expectation; the other solves the problem of how to get the optimal priority weight for supplier selection with genetic algorithm (GA), which is an efficient and flexible method for calculating the priority weight of the judgement matrix. Finally, an example for supplier selection is used to illustrate the effectiveness of the proposed methodology. H. M. W. Chen et al. proposed a comprehensive fuzzy multicriteria decision-making (MCDM) approach for green supplier selection and evaluation, using both economic and environmental criteria. In the proposed approach, a fuzzy analytic hierarchy process (AHP) is employed to determine the important weights of criteria under vague environment. In addition, a fuzzy technique for order performance by similarity to ideal solution (TOPSIS) is used to evaluate and rank the potential suppliers. Finally, a case study in Luminance Enhancement Film (LEF) industry is presented to illustrate the applicability and efficiency of the proposed method. T. Cheong et al. investigated how the choice of coopetition of the simultaneous pursuit of collaboration and competition dynamically impacts both the participating firms and the other self-developing ones in the same market. A conceptual framework of mathematical models obtained from the arguments and insights in the literature is used to undertake an in-depth study through a multiperiod analysis from 2013 to 2020 of an exemplar case of coopetition, the two concurrently ongoing coopetition partnerships in the US electric vehicle (EV) market, the Tesla Motors-Daimler AG alliance and the Tesla Motors-Toyota alliance, and the other firms which are not involved in coopetition.

\section{Supply Chain Network Design}

J. A. Marmolejo et al. proposed distribution network which includes three stages: manufacturing centers, consolidation centers using cross-docking, and distribution centers. The problem is formulated using a mixed-integer programming model in the deterministic and single period contexts. A primal-dual decomposition known as cross decomposition is also proposed in this paper. This approach allows exploring simultaneously the primal and dual subproblems of the original problem. A comparison of the direct solution with a mixed-integer lineal programming solver versus the cross decomposition is shown for several randomly generated instances. M. S. Habib et al. presented the review on the mathematical contributions made in the last decade in the field of humanitarian supply chain. A systematic literature review methodology is used for this paper due to its transparent procedure. Two objectives were set for this study: the first one is to conduct an up-to-date survey of mathematical models developed in HSC area and the second one is to highlight the potential research areas which require attention of the researchers. N.-R. Xu and J.-B. Liu presented three concepts including node strength centrality, betweenness centrality, and network centrality. They are used to calculate the weight of node enterprises in the agile supply chain network. And then, a series of agility indicators are designed to evaluate agility of agile supply chain network. AHP is used to calculate the weight of the indicators. Next, these indicators are used to get initial agility evaluation matrix by means of Delphi method, Data Mining, and so forth. Then FCE is used to calculate the membership degree on agility of node enterprises by combining the evaluation matrix with the weight of indicators. Last, the evaluation result of comprehensive agility of agile supply chain network is calculated on the basis of considering the weight of node enterprises. Another article by N.-R. Xu et al. established the evolutionary mechanism model of agile supply chain network by means of complex network theory which can be used to describe the growth process of the agile supply chain network and analyze the complexity of the agile supply chain network. S.-Y. Lim and S. Hur considered shipping problem of determining the optimal quantity of perishable products with a limited time to be stored in the warehouse. The optimal quantity minimizes the overall operational costs including those of inventory and shipping. A mathematical model is developed, from which the probability distribution function, mean, and variance of the length of the build-up period are derived and we establish a cost function for determining the optimal shipping value. Y. Lee and S.-C. Rim proposed an extended visibility concept focusing on a process capability perspective and suggested a more quantitative model using $Z$ score in Six Sigma methodology to evaluate and improve the level of supply chain visibility.

\section{Logistics Management}

C. Kim and S. W. Kim identified the factors of complexity due to the globalization of supply chain and to measure the management efficiency of the factors which cause the supply complexity within supply chain. This study conducts an analysis to utilize linear programming and bootstrapping, targeting 12 Korean companies among the selected companies in Fortune Global 500. The research findings reveal that public companies with the small number of products, factories, and providers relatively manage the supply complexity compared to private companies. Moreover, this study suggests projection point as a direction for relatively less efficient companies and excess quantity of input which should reduce for its achievement. This study also has an implication to establish a further standard of efficiency to manage the supply complexity for companies. J. Gang et al. focused on a multidemand multisource order quantity allocation problem with multiple transportation alternatives. To solve 
this problem, a bilevel multiobjective programming model under a mixed uncertain environment is proposed. Two levels (upper and lower) of decision makers are considered in the model. To solve the bilevel model, a solution method based on Kuhn-Tucker conditions, sectional genetic algorithm, and fuzzy random simulation is proposed. Finally, the applicability of the proposed model and algorithm is evaluated through a practical case from a large scale construction project. The results show that the proposed model and algorithm are efficient in dealing with practical order quantity allocation problems. Q. Qu et al. combined the characteristics of marine logistics industry and innovative technology professionals to design a performance evaluation index of marine logistics industry in innovation and technology professionals, with the analytic hierarchy process (AHP) to determine the weights of the various performance indicators and through the establishment of fuzzy comprehensive evaluation model to make the problems of complex performance evaluation quantification and then come to their performance evaluation results and provide reference methods and recommendations for innovation and technology professionals in performance evaluation theory and practice of marine logistics industry. Y. Sun and M. Lang explored a freight routing problem wherein the aim is to assign optimal routes to move commodities through a multimodal transportation network. This problem belongs to the operational level of service network planning.

Young Hae Lee Paulina Golinska-Dawson Jei-Zheng Wu 


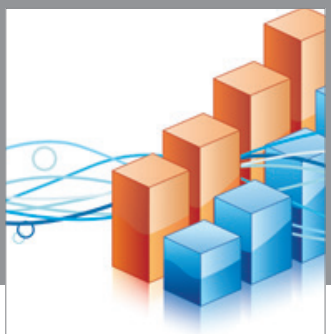

Advances in

Operations Research

vatem alat4

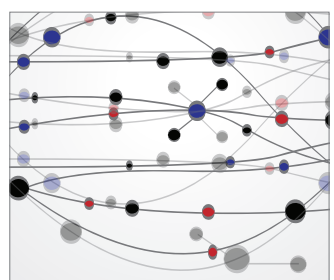

\section{The Scientific} World Journal
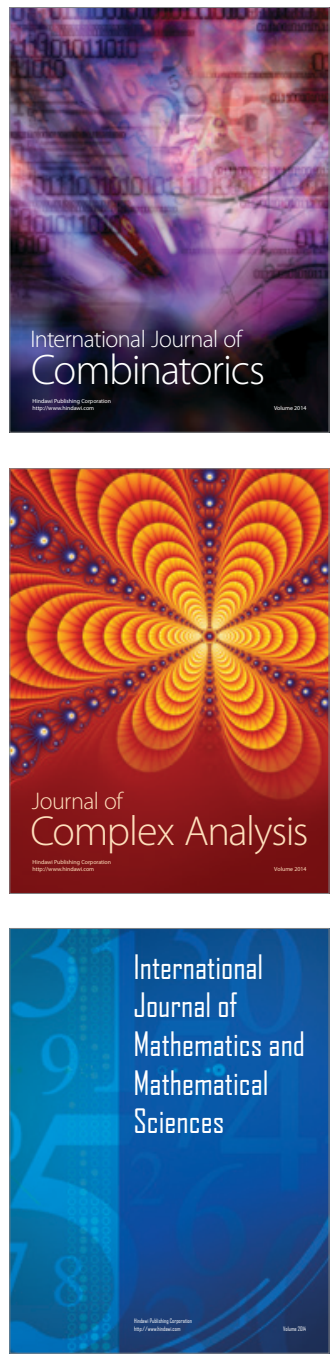
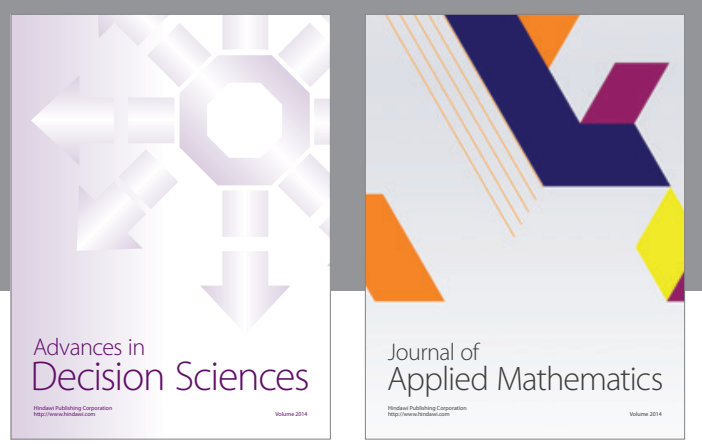

Algebra

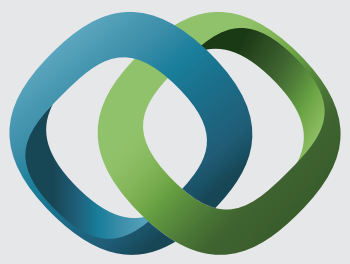

\section{Hindawi}

Submit your manuscripts at

http://www.hindawi.com
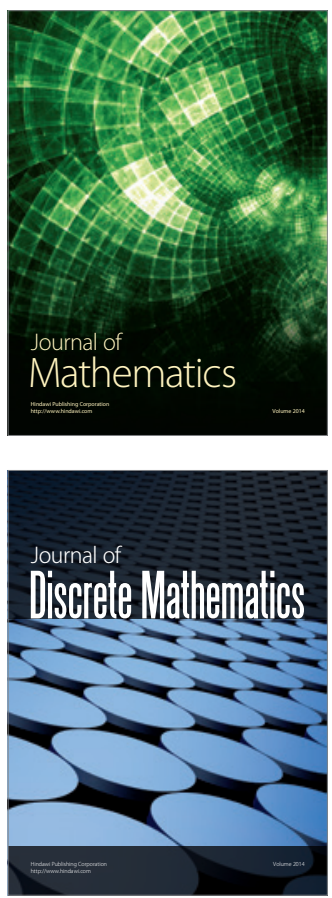

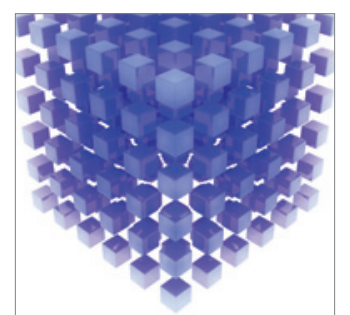

Mathematical Problems in Engineering
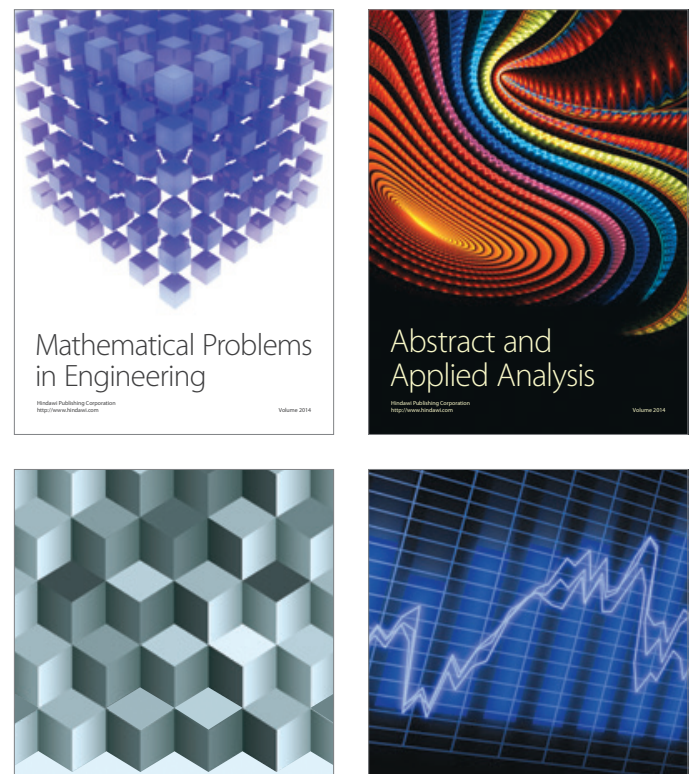

Journal of

Function Spaces

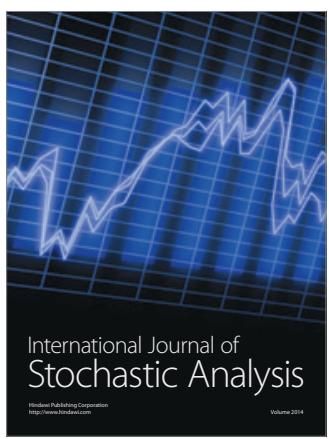

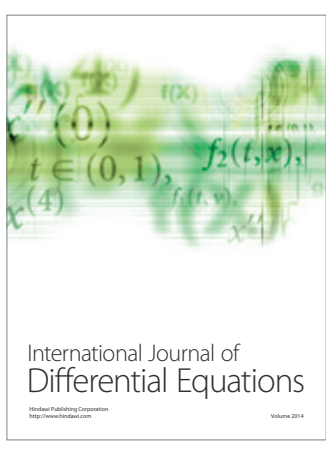
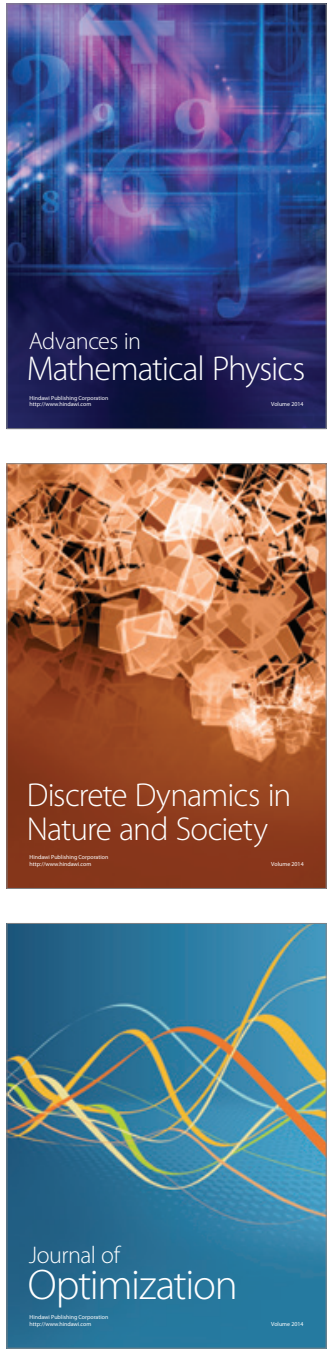